\title{
Culture-loaded Words and Translation Equivalence
}

\author{
Xuanxuan Zhou \\ University of Shanghai for Science and Technology, Shanghai 200093, China \\ Yan Hua \\ University of Shanghai for Science and Technology, Shanghai 200093, China
}

\begin{abstract}
Language and culture have very close relationship and can't dispense with each other. In translation practice, we must fully consider the cultural differences, and completely understand the meaning of the culture-loaded words, try our best to convey the information as much as possible, and realize translation equivalence and cultural exchange.
\end{abstract}

Index Terms - culture-loaded words, cultural connotations, translation equivalence

\section{INTRODUCTION}

Language is a part of culture; it is the carrier and image of culture. The distinctive cultural traditions of human society are reflected in language. It can be said that different language cases have their own cultural imprints. Translation is a cross-language and cultural communication activity. It is a language activity that uses one language to accurately express the content of thinking expressed in another language. However, because the East and the West have different cultural backgrounds, the cultural information carried by the two languages is not the same. In other words, there are cultural differences in language. The famous American translation theorist Eugene A. Nida (1993) said in his book "Language, Culture and Translation": "The role of language in culture and the influence of culture on the meaning of words and idioms It is so universal that no text can be properly understood without careful consideration of the language and cultural background."(Eugene A. Nida, 1993, p19) Holland, M. and N. Quinn (eds.)(1987) also argues it. The famous Russian translation theorist Juri Lotman (2006) said: "There is no culture It is not rooted in a specific culture; there is no culture that is not centered on a certain natural language structure."(p98) It can be seen that language and culture are inseparable. Zhuang Enzhong. (2007) argues that without language, culture cannot be reflected and existed. And language has meaning only when it reflects its culture. Therefore, in translation practice, the translator must have a thorough and detailed understanding of the differences between the Eastern and Western cultural backgrounds, and use various compensation methods to accurately, completely and effectively express the various cultural information carried by the words. Hu Meizhu, Xiao Hui (2006) argues it is possible to achieve equivalent translation.

\section{TRANSLATION EQUIVALENCE THEORY}

Translation equivalence is a core concept in Western translation theory. Since the 1950s and 1960s, many translation theorists have regarded this theory as an important part of their translation theory system. In the UK, Catford (1911) was the first to officially propose equivalent translation. He believed that "translation is the replacement of textual material in one language with textual material in another language equivalent to it."(p199)As a well-known American translator, Eugene Nida (1993) based on his own personal experience in translating the Bible, when discussing the nature of translation, he said: "Translation refers to the most approximate natural equivalent of the information in the source language copied by the receiving language, first in terms of definition, and second in terms of style. On the one hand, the translator must strive to achieve equivalence rather than identity. In a sense, this emphasizes copying rather than preserving the form of discourse. "(p200) It can be seen that what Cadford emphasizes is "textual equivalence", while Nida emphasizes "dynamic equivalence". In any case, they regard translation as a science. Their definitions of translation are all around the central word "equivalence". However, they have repeatedly emphasized that "absolute equivalence is impossible." "The so-called equivalent translation can only be based on absorbing the research results of culture, cognition, language and other disciplines, and rationally handle the problems of structure, meaning, culture, cognition and pragmatics, so that the original language can be compared with the target language. Try to be equal as much as possible. It can be seen that the loss of cultural information is inevitable in the translation process, and the key is to minimize this loss and keep the translation and the original content as equivalent as possible. 
Vocabulary is the most active and active language element in language, which can reflect the changes and development of social life and social thought very sensitively and quickly. Language is a cultural storage function that is directly displayed through words, reflecting the characteristics of its national culture. Li Zhaoguo (2003) and Li Yue (2006) argue the meaning expressed by vocabulary can be divided into two categories: one is denotation, that is, literal meaning; the other is connotation, that is, the implicit meaning of words, which explains the cultural connotation of words, also known as culture vocabulary. Each word represents a certain object or phenomenon. Different cultures have different expressions of the same object or phenomenon in language. This is due to the unique development history, social system, ecological environment, and religious beliefs, national customs of different countries or nations. Therefore, in translation, we must deeply understand the meaning of those culturally loaded words, and try to make the translation "close" and "naturally" reproduce the original text. The similarities and differences in the connotation of culturally loaded words are mainly manifested in the following aspects:

\section{A. English and Chinese Words Indicate the Same Meaning and Have the Same Meaning}

Although different nationalities have different cultural backgrounds and living habits, they also have something in common in the thinking process, which is what we usually call "commonality". This commonality is reflected in words and produces the same or similar semantics. For example, in Chinese, "fox" stands for cunning. People say "a fox can't be a civet cat" when they say that someone can't be an old man. People will also call those old treacherous people "old fox". In English culture, the word "fox" also has the same insidious and cunning meaning. Such as: The fox is known by his brush. (Look at the tail to know that it is a fox.), When the fox preaches, then take care of your geese. (Fox preaches, beware that the geese is only stolen.) Another example, in English and Chinese. The dove in the language symbolizes peace; the ivory tower refers to the small world of writers or artists who have broken away from social practice. In English, there are Walls have ears. (The walls have ears.) "Walls have ears" began at the Louvre in Paris. The Louvre was originally the Palace of the Kings of France. It is said that there are mysterious sound channels installed in its walls for eavesdropping. During the regency of Queen Catherine, she relied on this kind of "eared" wall to eavesdrop on the words of suspicious ministers; in ancient China, the book "Guan $\mathrm{Zi}$ - Under the Monarch and Ministers" said: "The wall has ears, and the wall has ears. It is also called the leaking of micro-conspiracy." Both English and Chinese have used the metaphor of a wall with a long ear to describe that a secretly discussed matter has been overheard, both based on their own allusions.

\section{B. English and Chinese Words Indicate the Same Meaning, But the Connotative Meaning Is the Same}

Different nations have the same associations for certain things in some aspects, but they also have different associations in some aspects. Murray (1990) and Tan Zaixi (1986) argue this view. For example: rose means love in both English and Chinese, and it means romance. But in English, there is an idiom "under the rose", which means secret and silence. This reflects an ancient habit in English history, that is, hanging a rose above the conference table means that participants must keep secrets. For another example, in both English and Chinese, spring means the first season of the year. In Chinese, "春" can mean "beautiful, happy, and sweet". Therefore, in Chinese, there is: 春风得意, Spring is full of spring, everything is spring, etc. In English, spring also has roughly the same meaning. This is why spring (spring) has become the object of praise for many writers. The most typical is the famous British poet Percy Bysshe Shelley (Percy Bysshe Shelley)'s famous phrase "If Winter comes, can Spring be far behind?"'However, in Chinese, "spring" also means "male and female love, male and female eroticism". In English culture, there is no such meaning. Another example: vinegar has the meaning of "acid" in both English and Chinese, but in Chinese, "vinegar" also means "jealous". For example, there is a saying in "A Dream of Red Mansions": People are vinegar jars, she (Wang Xifeng) is vinegar jars, vinegar urns. In English, vinegar means bad temper and unpleasantness. Such as: vinegar sb's speech (the unpleasantness revealed in someone's speech).

\section{English and Chinese Words Indicate the Same Meaning But Different Connotative Meanings}

Because people from the East and the West have different cultural backgrounds, living habits, ways of thinking, and aesthetic appeals, the same word has different values in different cultures, and has different connotations, that is, different associative meanings. For example, "Cuckoo" and "Crane" have different association meanings in Eastern and Western cultures. The cuckoo is often a symbol of "sorrow, sorrow, and sorrow" in Chinese classical literature, and the crane is a symbol of longevity in China, such as "Songhe Yannian". For Westerners, "Cuckoo" and "Crane" do not have the associated meaning of these images. "Crickets" in Chinese are associated with sadness and loneliness. Ouyang Xiu, $\mathrm{Du} \mathrm{Mu}$, and Yue Fei all use crickets to express sad feelings. However, in Anglo-American culture, the associative meaning of cricket is not only without sadness, but also joy and happiness. Such as "as merry as cricket". Another example is the most common animal "dog". In Chinese Han culture, people are the masters of dogs, and dogs are slaves of people. "Dog" is an object of contempt and curse. Almost all terms related to "dog" carry derogatory meanings, such as: dog bile God, the dog jumps the wall in a hurry, the dog's blood sprinklers, the dog is arrogant, the dog looks low, the dog can't vomit ivory, and so on. But in Western culture, dogs are good friends of man, and their "status" is much higher. Therefore, when someone is lucky, people will say "You are a lucky dog." which means: "You are a lucky dog." When someone is tired, he will say: "I am dog -tired." means: "I am tired."; when someone feels that he is getting old and can't learn new things, he will say: "I am too old dog to learn the new tricks." means: "I am too old to learn new 
things."

\section{English and Chinese Words Indicate Different Meanings and Have the Same Meaning}

Sometimes in Eastern and Western cultures, people will use different meaning words to express the same or similar cultural connotations, that is to say, the body is different, but the metaphor is the same. For example, "to meet one's Waterloo" in English originated from the fiasco of Napoleon in the Belgian town of Waterloo in the 19th century. In Chinese, "to meet one's Waterloo" refers to the ancient three kingdoms of Shu Guan Yu who was defeated and retired. For one thing, the two words are derived from different historical events, but have the same meaning, and both refer to tragic failure. There is also the Chinese "Blessings of Love" which means loyal love, while Westerners have Remeo and Juliet (Romeo and Juliet) loyal love. For another example, in English and Chinese, people usually use animals as vehicles to express the characteristics and qualities of characters. However, due to different social and cultural environments, they use words with different indicating meanings. Such as: as strong as a horse, lion hearted, as timid as a rabbit, as stubborn as a mule, a black sheep, to cast pearls before swine (playing the piano to the cow), as stupid as a goose (stupid as a pig), etc. It can be seen that the demonstrative objects in the original language are obviously different from the comparable objects in the target language, but they have similar meanings and have the same meaning and communicative function.

\section{E. English and Chinese Words Indicate the Same Meaning but Different Cultural Values}

Each language has its own national cultural value orientation, which reflects different ideas on the views and understanding of words or problems. There is a sentence in English: "Words do not have meanings, people have meanings for words." This sentence can be literally translated as: Words have no meaning, meanings follow life. Its deep meaning is to say that the connotation and values of words depend on the speaker's viewpoint, position and feelings, and the speaker's position, viewpoint and feelings are formed in the history and culture of the society in which he lives. For example, individualism is usually translated as "individualism" in Chinese culture, which refers to the self-interested thinking of oneself and disregard of others. In Western countries, people generally regard individualism as a positive manifestation of individual self-worth and a synonym for hard work and enterprising. Individualism is the core value of American culture. For more than two hundred years, the United States has always placed respect for individual rights and individual values in a very important position. Self-reliance, like seizing the initiative when doing things, having the courage to express different views and respecting the privacy of others are all manifestations of individualism. For another example, when used in philosophical terms, materialism means "materialism" and idealism means "idealism". Due to the different perspectives, standpoints, and concepts that people look at the problem, these two words are not good or bad or praise or criticism in English. In Chinese, they are positive for materialism, but negative for idealism. Yan Hongen (1985) argues that the connotative meaning of these words is not inherent in these words, but is given to them by people according to their own background and cultural atmosphere.

\section{Methods to Achieve "TransLation EQuivalent"}

It can be seen from the above analysis that words carry rich cultural connotations. Their commonalities and individuality can produce different word meaning associations in their indicative sense. This cultural difference adds a certain degree of difficulty to translation. This difficulty is mainly reflected in the lack of vocabulary and the conflict of word meaning, that is, the cultural information carried by the original words. Wang Jinjuan (2006) and Yu Jianping (2000) argue that the cultural information carried by the corresponding words of the language is contradictory or inconsistent. That is to say, the meaning of the surface of the word is the same, but the cultural connotation carried by the deep meaning of the word is not the same or even completely contradictory, so completely different associations are produced. As the famous British translation theorist Peter Newmark (1946) said: "The stronger the cultural (local) and temporal distance of a text, the more incredible the (translation) equivalence will be."(p11) In other words, That is, the greater the cultural difference between the original language and the target language, the more difficult it is to convert the equivalence between the two languages, and the more the equivalence validity is affected.

As a pioneer of cultural exchanges between various ethnic groups, translators must have a thorough and detailed understanding of the differences in cultural backgrounds between the East and the West, and use various compensation methods to accurately, completely and effectively express the various information brought by cultural factors. Try to achieve equivalent translation as much as possible. In the process of translation practice, usually the following methods of adaptation and compensation can be used for translation: literal translation, transliteration, free translation, literal translation and annotation, literal translation and free translation, transliteration and annotation and set translation, etc.

\section{A. Literal Translation}

Although literal translation focuses on the translation of the original text sentence, it is not a one-to-one translation, but a literal translation, without too much extension and annotation. Literal translation is a commonly used method in translation. Under the circumstance of not violating the target language norms and causing wrong associations or misunderstandings, literal translation shall be adopted as much as possible, and the image and customary expression methods in the original text shall be retained to the greatest extent, so as to retain the foreign characteristics of the 
original text and not only make the translation fresh and powerful, And opened the eyes of the target readers, as if to feast on a delicious meal with exotic flavors. For example, the Golden Rule of Jesus Christ to his disciples is "Do as you would be done by." (How you want others to treat you, you also have to treat others.) This is the same as the famous Chinese Confucian saying. It's almost exactly the same, coincidentally. There are many other idioms that can find almost corresponding words in both English and Chinese. Such as: to pour oil on the flame, Strike while the iron is hot. to praise to the skies, to fish in the troubled water, walls have ears, There is no smoke without fire. (No waves without wind.), Bad workmen often blame their tool etc. This corresponding translation not only retains the vivid metaphors and strong cultural atmosphere in the original language, but also because the translation comes from the more vivid idioms and expressions in the target language culture, the translation is more easily accepted by readers.

\section{B. Transliteration}

With the rapid development of society, new things have sprung up like mushrooms after rain, and these will inevitably be reflected in the language. Therefore, when no equivalent words corresponding to the original language are found in the target language, transliteration is usually used. Such as disco, Internet, hamburger, clone, sanna, nylon, sonar, copy, brandy bikini, hot dog, black horse, engine, motor, sofa etc. These words belong to the transliteration method, and they have gradually entered the Chinese culture; the same Chinese words "kowtow" , "typhoon" , "Qigong", ""Wushu" "paper tiger", "Mahjong" and" Litchi" have gradually entered English culture. The use of transliteration can enrich the language, help the communication and development between the two languages, and $\mathrm{i} s$ the best translation method for foreign words.

\section{Free Translation}

Due to the cultural differences between the East and the West, some words will have very strong cultural significance. If the literal translation method is used blindly, it will not only fail to accurately convey the information contained in the original text, but also make the target readers confused or even misunderstood. In order for the target readers to obtain the same cultural information as the original readers, the only way to abandon the "likeness" is to pursue "likeness", that is, not to stick to formal correspondence, but to faithfully reproduce the main meaning of the original text and highlight its connotation. The translator must look for suitable expressions in the target language culture, make various necessary conversions, and perform free translation to achieve functional equivalence. Such as: It was another one of those Catch-22 situations, you're damned if you do and you're damned if you don't. (This is really another awkward situation, it's bad luck to do it, bad luck not to do it.) The word Catch-22 in the text has become a lingua franca in European and American societies, and is widely used daily, and is also included in dictionaries. It has officially become a word in modern English. It comes from the title of the novel by Joseph Heller (1923-1999) (Chinese translation is "The Twenty-Second Military Regulations"). The novel is a fictional story about an American bombing squadron stationed in the Mediterranean during World War II. On the surface, it is about the crazy behavior of air force officials. In its essence, it reflects the ignorance, unreasonableness and ignorance of large institutions and those in power. The author ruthlessly lashes at social injustices with the brushwork of laughing and cursing. If it is directly translated as "Catch-22", Chinese readers may not be able to fully understand it. It is better to translate it into "dilemma and embarrassment." There is also the English idiom "rain cats and dogs", which some people think the source of this idiom From Norse mythology, it is believed that the storm is the cat and dog, and some people think that the storm is the cat and dog fighting. No matter how you say it, there is no corresponding expression method for this kind of saying in Chinese. It is impossible to transplant the idiom into Chinese literally or literally, so a free translation can be used, which can be translated as "大雨 浐沱”或“大雨倾盆”. The same is true for Chinese, such as "Dongshi imitates Xishi", if it is simply translated as "Dongshi imitates Xishi", the meaning in the original text is not translated at all. Since Chinese readers understand the specific cultural meanings of Dongshi and Xishi, they are completely understandable. However, for foreign readers, it may be confused and at a loss. Therefore, in order for the target readers to understand the exact meaning of "Dongshi Xiaoying", free translation is needed. Can be translated as: "The ugly imitates the beautiful in such a distorted way that the ugliness of the ugly becomes worse.". Another example is "Drink the northwest wind" in Chinese. If it is literally translated as "drink the northwest wind", it will be difficult for readers to understand, so it can only be translated as "have nothing to eat". Similar translations in English include "A watched pot never boils." (Anxious water does not boil.), "Every bean has its black." (Every mortal has its shortcomings.), "A friend in need is a friend indeed "(See the truth in adversity.) etc.

\section{Literal Translation and Annotation}

In the process of translation between English and Chinese, sometimes some culturally loaded words need to provide a certain cultural background, so as to help the target readers to better understand the cultural connotation of the original language and enhance the understanding of the original. It can usually be processed by literal translation and annotation. Such as: "Chinese descendants" in Chinese, it can be translated as: the offspring of Huaxia. "Huaxia", or the short term "Hua", was the ancient name of China. In ancient times people living in control China used to call their native land "Huaxia", which is now used as a synonym for the Chinese nation or China. Another example is Promethean heat in English. Translation: Promethean God Fire, Prometheus is a hero in ancient Greek mythology who stole fire from Mount Olympus to mankind. 
Because of the two different cultures of English and Chinese, the names, place names, ages, customs, classics, allusions, etc. involved in their languages will have their own unique color associations in the process of historical formation. When translating such words, usually this method of literal translation and annotation can be used to firstly introduce new expressions in foreign languages, and secondly to fill in the vocabulary "vacancies" in the target language.

\section{E. Literal Translation and Free Translation}

Sometimes in the translation, some idioms with historical knowledge or strong cultural flavor will be encountered. If you only translate it, you may lose the vivid metaphorical color of the original language. It is best to literally translate the image of the original idiom and add the free translation. It not only retains the image metaphor in the original language, but also can be accepted by the target language readers. This form of translation is a "hybrid" of literal translation and free translation between the two parts before and after the introduction and annotation. Such as: While it may seem to be painting the lily, I should like to add somewhat to Mr. Alistair Cooke's excellent article. (March: Guakdian Weekly, 19 Feb. 1953) (ALIstair Cooke's Mr. Cooke A few strokes of the masterpiece, although this may be coloring the lily, which is not thankful.) In the translation, painting the lily is literally translated, preserving the original cultural image, and then explaining its connotation. This processing method is just right, it preserves and reproduces the vivid image of the original text. Lilies are regarded as a symbol of chastity, innocence, and purity in Christian art; in the eyes of Westerners, lilies are beautiful and noble, so coloring lilies is futile. If it is only translated as "one extra effort" or "futility", although the meaning is similar, the cultural difference is completely lost. The image of lily is retained in the translation, and the readers of the translation will explore the symbolic meaning according to the prompts, so as to experience the differences between Chinese and Western cultures in this respect, and expand the readers' knowledge and experience. Another example: Men sent flowers, love notes, offers of fortune. And still her dreams ran riot. The one hundred and fifty! The one hundred and fifty! What a door of an Aladdin's cave it seemed to be. (Th, Dreiser, Sister Carrie) (The man sends flowers, love letters, and luck to her. But she still has endless dreams. This one hundred and fifty dollars! This one hundred and fifty dollars! It really seems that the cave with the magic lamp has been opened for Aladdin Door. The last sentence uses the method of literal translation and free translation to fully present the meaning of the Aladdin story, which helps the target readers understand the exact meaning of the sentence. The following sentences also use the method of literal translation and free translation. "Fish begins to stink at the head." (The fish must rot and the head will stink first-the upper beam is not straight and the lower beam is crooked.) "The best fish swim (are) near the bottom." (Good fish swim (are) near the bottom." Obtained.) "A bull in a china shop." can be translated as: "Bull broke into the Ciqi shop-wantonly make trouble.", "Can the leopard change his spots?" can be translated as "Leopard can't change the markings on his body-- Nature is hard to move." "To shed crocodile tears." can be translated as: "Crocodile tears-false mercy." "Achilles' heel." can be translated as: "Achilles' heel-the only weakness."

\section{F. Transliteration and Annotation}

In translation practice, we sometimes encounter conceptualized names or words involved in the original language. These conceptualized names or words are very easy to understand for the readers of the original language, but for the target readers, due to the lack of understanding The understanding of the original language and culture is difficult to understand, or even completely incomprehensible. In this case, it is necessary to add appropriate explanatory text to help readers understand the translation. For example, the Chinese word "班门弄斧" can be translated into English as " to show off one's proficiency with the axe before LuBan, the master carpenter." An explanatory word has been added to the translation, the master carpenter, which has become a skilled craftsman in Luban, China Pronouns, but foreign readers do not know it. After adding annotated text, the information in the original language is fully reflected. For another example, on December 18, 2008, General Secretary Hu Jintao delivered an important speech at the meeting to commemorate the 30th anniversary of reform and opening up. There was a paragraph in which he said: "Our great goal is to build the party and benefit from a well-off society of a higher level with a population of more than one billion will be basically modernized by the 100th anniversary of the founding of New China and become a prosperous, democratic, civilized and harmonious modern socialist country. As long as we are unwavering, unswerving, and unswerving by advancing reform and opening up, and unswervingly following the path of socialism with Chinese characteristics, we will surely be able to triumphantly achieve this magnificent blueprint and goal." What does "not toss" in the text mean and how to translate it. In addition to the translation version of China Daily, which translates "不 tossing" into "don't get sidetracked" and "don't sway back and forth", there are also various translations circulating on the Internet, such as: don't flip flop; no dithering; no major changes; avoid futile actions; stop making trouble and wasting time and so on. The interpreter version of the State Council Information Office transliterates "bu zhe teng" into "bu zhe teng". The author thinks that the method of transliteration and annotation is more appropriate. If you simply use transliteration, foreign readers may not know what it is. If you only use free translation, although foreign readers understand the meaning, the translation loses the original cultural flavor. Therefore, the author believes that using transliteration and annotation is a better method, which can be translated as Bu zhe teng ----don't sway back and forth. This not only retains the vivid cultural color of the original text, but also accurately displays its meaning.

\section{G. Set Translation Method}


Sometimes in the original language and the target language, there are quite a few expressions that are completely equivalent or similar in meaning, and these expressions do not contain a strong cultural color. And there are corresponding words in the target language, which are completely consistent and corresponding in content, form, metaphor, rhetoric, etc. In this case, you might as well apply the idioms in the target language straightforwardly. In this way, you can keep the original idiom's style, and make the translation more vivid and smooth, and at the same time, it can be more accepted by the target readers. For example, in English, "Barking dogs do not bite." (Barking dogs do not bite.) "When the cat's away, the mice will play." (Cat's away, the mice will play.) "To spend money like water." (Spend gold like earth.) "At sixes and sevens." (Chaos.) "Love me, love my dog." (爱屋及乌) "Time is money." (An inch of time and an inch of gold.) "Money makes the mare go." (Money can make ghosts grind.) "Great men are apt to have short memories." "He who has a mind to beat his dog will easily find his stick." No words.) "Great minds think alike." (The hero sees the same.), "Like begets like." (Long begets like dragon, Feng begets like.), "Look before you leap." (Think before you leap.) Wait.

\section{CONCLUSION}

In short, the words of different nationalities always have their own specific cultural connotations. The cultural connotations we are talking about are also a general and broad complex, which penetrates into all psychological processes and psychological behaviors of human society, from materials to ideas, from individuals to individuals. Society, from politics to religion, etc., constitutes the entire cultural ecological environment, and any element of this environment may be reflected in the meaning of words. The essence of translation is to allow people to understand and understand the cultural life and emotional ways of other nations through translation. Therefore, when translating these culturally loaded words, we must pay attention to the preservation of the cultural color in the original text and be able to handle the cultural load flexibly and effectively. The translation of words can fully demonstrate the thinking characteristics of different ethnic cultures and their emotional ways, so as to achieve the equivalent or approximate equivalent of cultural information and final effects, and achieve greater cultural transplantation and cultural exchanges.

\section{REFERENCES}

[1] Eugene A. Nida. (1993). "Language, Culture and Translating" Shanghai: Shanghai Foreign Language Education Press.

[2] Holland, M. and N. Quinn (eds.). (1987). "Cultural Models in Language and Thought" Cambridge: Cambridge University Press.

[3] Zhuang Enzhong. (2007). Xi an:"English and Chinese Cultural Words and Translation Processing", Journal of Xi'an International Studies University. Issue 1: 71--74

[4] Hu Meizhu, Xiao Hui. (2006). Nanjing:"Cultural Connotation and Translation of English and Chinese Words" Journal of Nanjing University of Finance and Economics. Issue 6: 97--100

[5] Li Zhaoguo. (2003). Shan dong:"Cultural factors in translation and the treatment of culturally loaded words" Journal of School of Foreign Languages, Shandong Normal University. Issue 3: 701---801

[6] Li Yue. (2006). "Looking at Translation Equivalence from Cultural Transplantation", Journal of Shonan University, Issue 2: $91-94$.

[7] Murray. (1990). "The Treatment of Cultural Differences in Idioms from the Perspective of Reception Theory" Chinese Translation, Issue 4: 9--14

[8] Tan Zaixi. (1986). "Cultural Contrast and Translation" "Chinese Translation" No. 5: 7-9

[9] 9. Yan Hongen. (1985). "A Preliminary Study on the Translation Skills of English Proverbs" Chinese Translation, Issue 6: 20-22.

[10] Wang Jinjuan. ( 2006). "Cultural Context and Translation" Shanghai Translator, Issue 2: 52--54

[11] Yu Jianping. (2000). Beijing:"The Influence of Cultural Differences on Word Meaning and Semantic Understanding in English-Chinese Translation". Chinese Translator, Issue 3, 27-29, Language Education Press, August

Xuanxuan Zhou was born in Shanxi Province, China. She is currently a postgraduate in the College of Foreign Languages, University of Shanghai for Science and Technology, Shanghai, China. Her major is Translation.

Yan Hua graduated from University of Shanghai for Science and Technology (USST) in 1996. She is currently associate professor at USST. Her research interests mainly are Australian Literature and Teaching Methodology. 